\title{
Blooming of Compounding Ingredients in Natural Rubber Compounds under Different Peroxide Loading
}

\author{
Ummu Qani’ah Yasin, Engku Zaharah Engku Zawawi, Noorazlina Adnan, Hairani Tahir and \\ Dzaraini Kamarun
}

\begin{abstract}
Rubber compounds normally shows blooming phenomena whereby a thin layer of powdery material or films and oils formed on the surface. These blooms are usually low molecular weight compounding ingredients such as curing agents, accelerator, processing aids and activators that migrated to the surface. Excessive blooming can degrade the vulcanized rubber and reduced its quality. It is therefore necessary to determine the compounding ingredients that bloomed in an effort to reduce the effect of blooming. This study was aimed at identifying the compounding ingredients that dominate the blooming process. Sulphur, paraffin wax and zinc diethyldithiocarbamate (ZDEC) with specific functions were added as compounding ingredients in natural rubber (SMR $L$ ). Dicumyl peroxide were added as the curing agent at several loadings. The rubber compounds were cured at $150^{\circ} \mathrm{C}$ in the presence of dicumyl peroxide as curing agent at several loadings. They were stored under room temperature for blooming to take place. Blooms were analysed using FTIR and EDX. EDX analysis detected the major element present in the blooms to be carbon at 53.5\% abundance. Similarly, FTIR results produced high intensity of $C-H$ band at $2916 \mathrm{~cm}^{-1}$ and $722 \mathrm{~cm}^{-1}$ which are due to stretching and bending vibration of $\mathrm{C}-\mathrm{H}$ paraffinic. It was concluded that paraffin wax preceded sulphur and ZDEC in blooming of SMR L.
\end{abstract} L.

Keywords: Bloom, Compounding ingredients, Peroxide, SMR

\section{INTRODUCTION}

Rubber compounds are complex mixtures, consisting of different compounding ingredients such as curing agents,

Manuscript published on November 30, 2019.

* Correspondence Author

Ummu Qani'ah Yasin, Orchestrated Polymer Research Group, Faculty of Applied Sciences, Universiti Teknologi MARA, Shah Alam, Malaysia..

Engku Zaharah Engku Zawawi", Orchestrated Polymer Research Group, Faculty of Applied Sciences, Universiti Teknologi MARA, Shah Alam, Selangor, Malaysia.

Hairani Tahir, Orchestrated Polymer Research Group, Faculty of Applied Sciences, Universiti Teknologi MARA, Shah Alam, Malaysia..

Noorazlina Adnan, Centre of Foundation Studies, Universiti Teknologi MARA, Cawangan Selangot, Kampus Dengkil, 43800 Dengkil, Selangor.

Dzaraini Kamarun*, Orchestrated Polymer Research Group, Faculty of Applied Sciences, Universiti Teknologi MARA, Shah Alam, Selangor, Malaysia.

(C) The Authors. Published by Blue Eyes Intelligence Engineering and Sciences Publication (BEIESP). This is an open access article under the CC-BY-NC-ND license

(http://creativecommons.org/licenses/by-nc-nd/4.0/) accelerator, processing aids, and activators; which may be in solid and/or liquid forms. Many of these compounding ingredients often blooms and diffuses to the surface during storage and service life [1]. Blooming in rubber may occur when partly soluble compounding ingredient is used at a level in excess of its solubility limit at a given temperature. Blooming is an outcome of a controlled diffusion process [2], while diffusion can be explained as a movement of soluble compounding ingredients driven by a distraction in the equilibrium. Solutions of the compounding ingredient in rubber compound are known to act similarly to solutions of low molecular weight liquids and are characterized by the same laws as for normal solutions. When the concentration of a soluble component at the interface of a liquid is reduced, the soluble component diffuses to restore concentration equilibrium. Consequently, diffusion provides the required protection to the rubber surface. Compounding ingredients do not bloom independent of need, but diffuses only when the surface concentration was reduced [3]. Almost all compounding ingredients which are soluble in rubber possess the tendency to bloom [4]. Blooming in rubber compounds can be disadvantageous. In production of multi-ply product such as tires, hoses, belts and other products; blooming reduces the tackiness of the rubber compound [5]. Blooming of sulphur materials on uncured rubber compounds gave rise to poor rubber-to-rubber or rubber-to-metal bonding [6]. The staining of light coloured rubber products due to migration of antioxidants to the rubber surface is an example of its reduced aesthetic appearance [7]. Blooming of the accelerator component to the rubber surface often extensively damages the internal structure of the rubber matrices; creating cracks and voids which weakened the rubber mechanically [8]. Blooming of compounding ingredients was explained in broad theoretical basis as outlined by Nah and Thomas [9]. These materials which bloom must have a limited but appreciable solubility in the rubber, and be present at a concentration greater than this nominal solubility at the storage or operating temperature of these rubber products. As the rubber vulcanizate cools post the vulcanization process, the available compounding ingredients will crystallize, and as the crystal grow within the rubber; regions of strain will be set up around the crystal. 
These strain regions increases as the crystals grow until no further crystallization can occur, eventually leaving a greater concentration of the chemical remain soluble in the bulk of the rubber than if there were no strains restricting crystallization [5].

Before we find the ways to overcome the blooming problem, we need to identify the component(s) that bloom readily to the surface. Studies on surface migration of individual compounding ingredients in vulcanized rubbers have been reported in the literature, but none were specialized on the dominancy of one ingredient over the other. This paper discussed the techniques used to identify blooms on NR vulcanizates which incorporate three typical ingredients i.e. sulphur, wax and ZDEC in NR formulation of rubber products. It is the aim of the study to determine which of these compounding ingredients dominate the blooming process in NR compound in a mix vulcanization system.

\section{MATERIALS AND METHODS}

\section{A. Materials}

Raw rubber used was the Standard Malaysian natural rubber grade L (SMR L), supplied by Malaysian Rubber Board (MRB). Crosslinking agent used was the Dicumyl Peroxide (DCP) with a melting point of $38^{\circ} \mathrm{C}$. The sulphur used was the soluble rhombic crystal type; while the wax used was paraffin wax. The accelerator used was Zinc Diethyldithiocarbamate or ZDEC (mp: $172^{\circ} \mathrm{C}$ ). Carbon black SAF N660 was used as a colouring agent.

\section{B. Compounding of Vulcanizates}

Mix vulcanizates were prepared using a conventional two-roll mill following ASTM D3182. The formulations of 3 samples prepared are tabulated in Table-I. This formulation was generated from using three types of compounding ingredients which were sulphur, wax and ZDEC at high loading (10 phr) under three different loadings of peroxide (1, 2 and 4 phr).

Table- I: Formulation of Mix vulcanizates

\begin{tabular}{|l|l|l|l|}
\cline { 1 - 2 } Compound & \multirow{2}{*}{ V1 } & V2 & V3 \\
\cline { 1 - 3 } Ingredients(pphr) & & & \\
\hline NR (SMR L) & 100 & 100 & 100 \\
\hline Dicumyl Peroxide & 1 & 2 & 4 \\
\hline Carbon Black & 5 & 5 & 5 \\
\hline Sulphur & 10 & 10 & 10 \\
\hline Paraffin Wax & 10 & 10 & 10 \\
\hline ZDEC & 10 & 10 & 10 \\
\hline
\end{tabular}

The rubbers were initially subjected to mastication using the two-roll mill for $3-4$ minutes before the compounding ingredients were added. The total mixing time was approximately 20 minutes. After mixing, sheets of rubber of thickness in the range of $2 \mathrm{~mm}$ were produced. The finished rubber compounds were kept at ambient temperature (25 $\pm 2^{\circ} \mathrm{C}$ ) for at least 24 hours.

\section{Preparation of Test Pieces}

Test pieces in the form of cylindrical disc $7 \mathrm{~mm}$ thickness were prepared using a compression moulding machine (Xiangjie, model: HP-50) during which the curing process took place. In compression moulding, weighed rubber compounds were placed into the cavity between the two halves of heated mould under pressure for a given time at the temperature of vulcanization. The temperature was $150^{\circ} \mathrm{C}$, while pressure varied from 20 to $70 \mathrm{MPa}$, at the optimum cure time.

\section{Blooming Test}

The initial weight of rubber disc was measured accurately using an electronic balance. The samples were then stored at ambient temperature $\left(27^{\circ} \mathrm{C}\right)$ in a tray that have been covered with soft gauze to avoid contamination from ashes. The samples were placed on their sides to prevent cross-transfer of the leachate from the rubber surface during storage. Blooms were collected at 24-hour interval by scrapping the bloom on the two surfaces and all sides of the cylindrical disc. The amounts of blooms as a function of time were monitored periodically at 24-hour interval until the weight of bloom remained constant. The mass of bloom collected were recorded.

\section{E. Identification of Bloom Composition}

To identify the dominant compounding ingredients that dominated the blooming process, the bloomed materials that were scrapped from the entire surface of V1, V2 and V3 vulcanizates were analysed with Energy-Dispersive- X-ray (EDX) detector connected to the FESEM SUPRA-40 VP INCA machine and Fourier transform infrared spectrometer (FTIR) (Perkin Elmer Spectrum 1A Diamond Stage ATR).

\section{F. Microscopic Observation of Bloom}

A Polarized Optical Microscope (Nikon- Leica SMZUME 600) and a SEM microscopic instrument (FESEM SUPRA-40 VP INCA) were used to examine the bloom that appeared on the surfaces of the rubber vulcanizates.

\section{RESULTS AND DISCUSSION}

Fig. 1 shows the amount of bloom collected as a function of time for vulcanizates V1, V2 and V3. As expected, the amount of bloom produced for all 3 vulcanizates increased with storage time. Increasing peroxide concentration increased the initial rate of bloom as can be seen from the gradient of the curves after 1 day. Both V2 and V3 show similar initial rate of bloom compared to V1. However the bloom phenomena of V2 stopped almost instantaneously after 1 day as the amount of bloom levels off. The amounts of bloom of $\mathrm{V} 2$ at saturation point almost equate that of $\mathrm{V} 1$. Nevertheless, bloom of V1 took longer time to saturate (12 days) compared to V2 (1 day). Amount of bloom of V3 compound continued to increase with time and produced the highest amount of bloom at saturation point of 9 days. Incorporation of high loading of peroxide cross-linker (4 pphr) does not seem to hinder the diffusion of bloom material to the surface as seen by the increase in amount of bloom for V3. The systems studied consist of a mix vulcanization of sulfur and peroxide. Cross-link density is lowest in a mix vulcanization system compared to peroxide system; and low cross-link density makes ease diffusion of monomers from a rubber compound [10]. It is therefore assumed that the cross-link density of all the compounds prepared in this study is not considerably high to impede diffusion of bloom to the surface. 


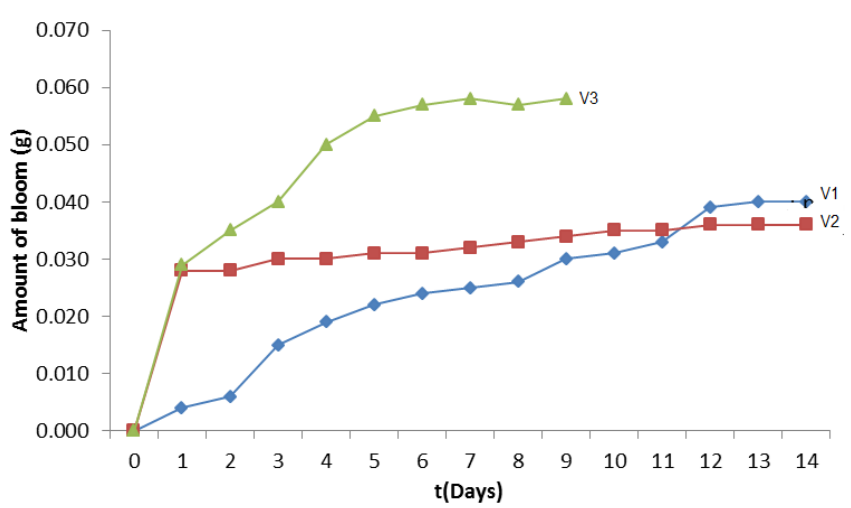

Fig. 1. Amount of bloom as a function of time for vulcanizates. (V1 (४), V2 (ロ) and V3( $\Delta)$ )

Fig. 2 shows the optical microscopic image of one of the vulcanizates. All vulcanizates show a layer of whitish material which is refered to the bloom observed upon storage.

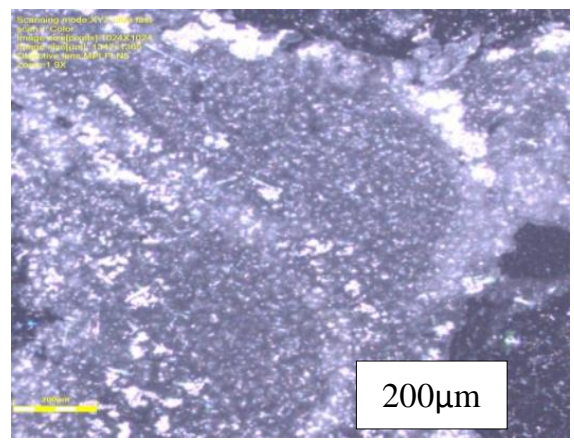

Fig. 2.Optical microscopic image of whitish material observed on the surface of vulcanizate upon storage.

FESEM images at $1000 \times$ magnification (Fig. 3) of V1 and $\mathrm{V} 3$ on $7^{\text {th }}$ day of storage show formation of mini cracks as blooming progressed. These cracks could be associated with degradation of the rubber samples as blooming takes place.

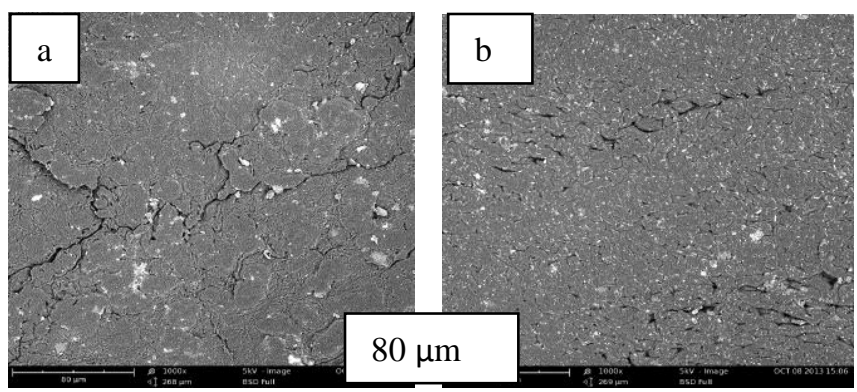

Fig. 3.FESEM images of ((a) V1 and (b) V3) after 7 days of storage

Fig. 4 shows the EDX spectrum of blooms collected from the all vulcanizates. There were two major elements detected by EDX analyser which were carbon (C), and oxygen (O). The broad peak detected in the spectrum was due to Aurum $(\mathrm{Au})$ since it is used as coating material during the sampling process. Therefore the presence of Au was neglected. 
Bands for DCP are detected at $698 \mathrm{~cm}^{-1}$ and $764 \mathrm{~cm}^{-1}$ which are due to C-H aromatic bending; and $1155 \mathrm{~cm}^{-1}$ due to C-O stretching (Fig 5(b)). Bands for ZDEC are at $2930 \mathrm{~cm}^{-1}$ due to $\mathrm{C}-\mathrm{H}$ stretching and $1206 \mathrm{~cm}^{-1}$ due C-N stretching (Fig 5(c)). For sulphur, major bands are at $844 \mathrm{~cm}^{-1}$ and $937 \mathrm{~cm}^{-1}$ (Fig 5(d)) which agreed with Neff and Walnut [11].
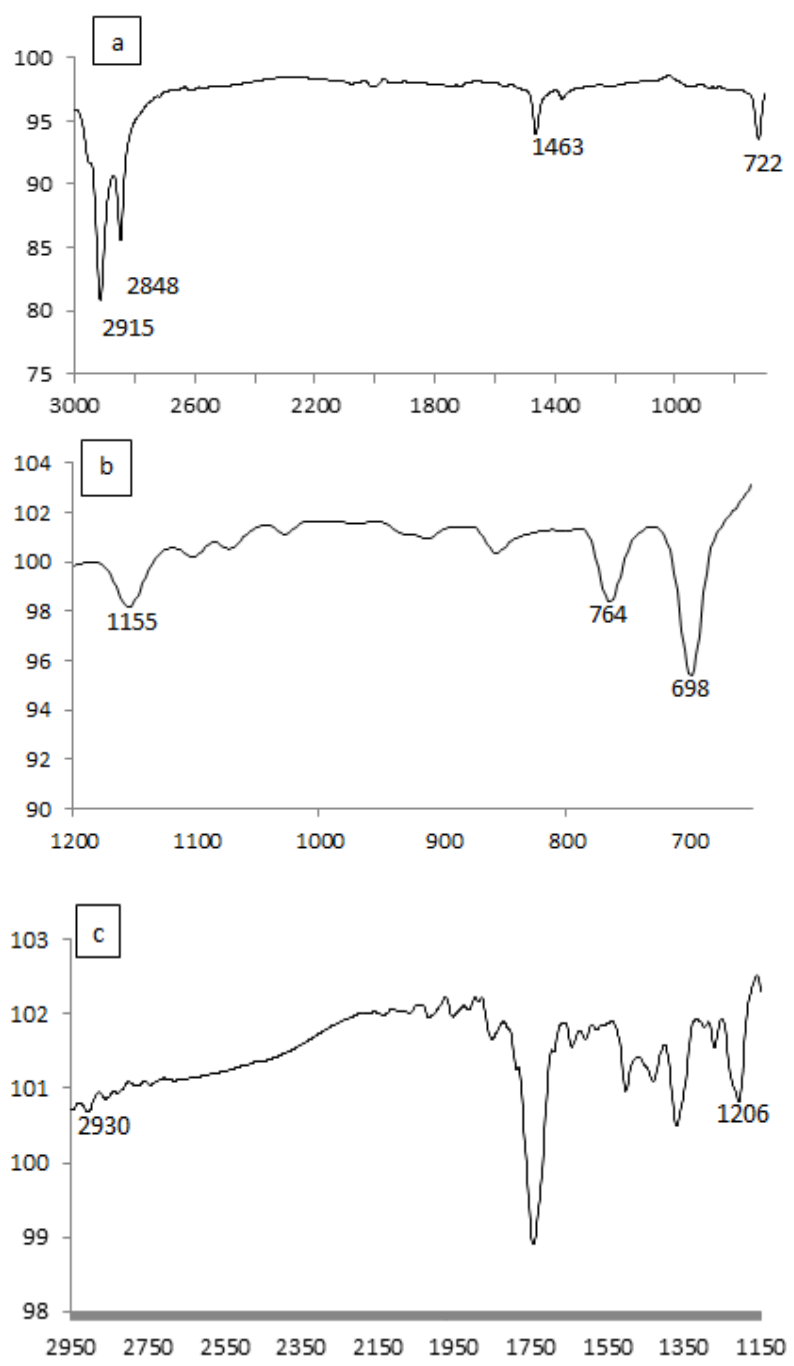

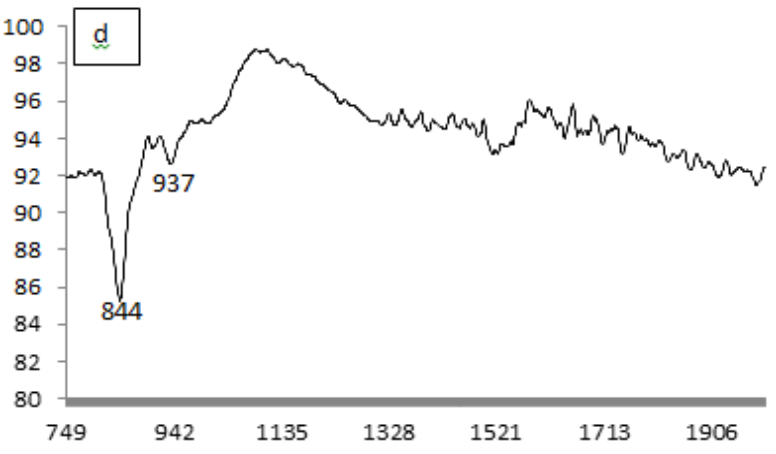

Fig. 5.FT-IR spectrum of (Paraffin wax (a), Dicumyl peroxide (b), ZDEC (c) and sulphur (d)).

Fig. 6 shows an overlay spectra of the mix vulcanizates with all of the ingredients present and spectra of the individual ingredients. Paraffin wax was identified to be the main compounding ingredients that dominate the blooming process. This is because the paraffin wax has poor solubility in rubber [5]. The melting temperature $\left(50-60^{\circ} \mathrm{C}\right)$ of paraffin wax was below the curing temperature of rubber and melted while the rubber was being cured at $150^{\circ} \mathrm{C}$. When the cured rubber was removed from the mould and cooled to ambient temperature, paraffin wax diffused to the rubber surface to form the bloom. The presence of paraffin wax in the bloom was expected, since it migrated to the surface to protect the rubber against environmental aging. The other compounding ingredients bloom less and it may due to the possibility of sulphur and ZDEC interacting with each other through polar interaction; thereby impeding the diffusion of sulphur and ZDEC to the surface.

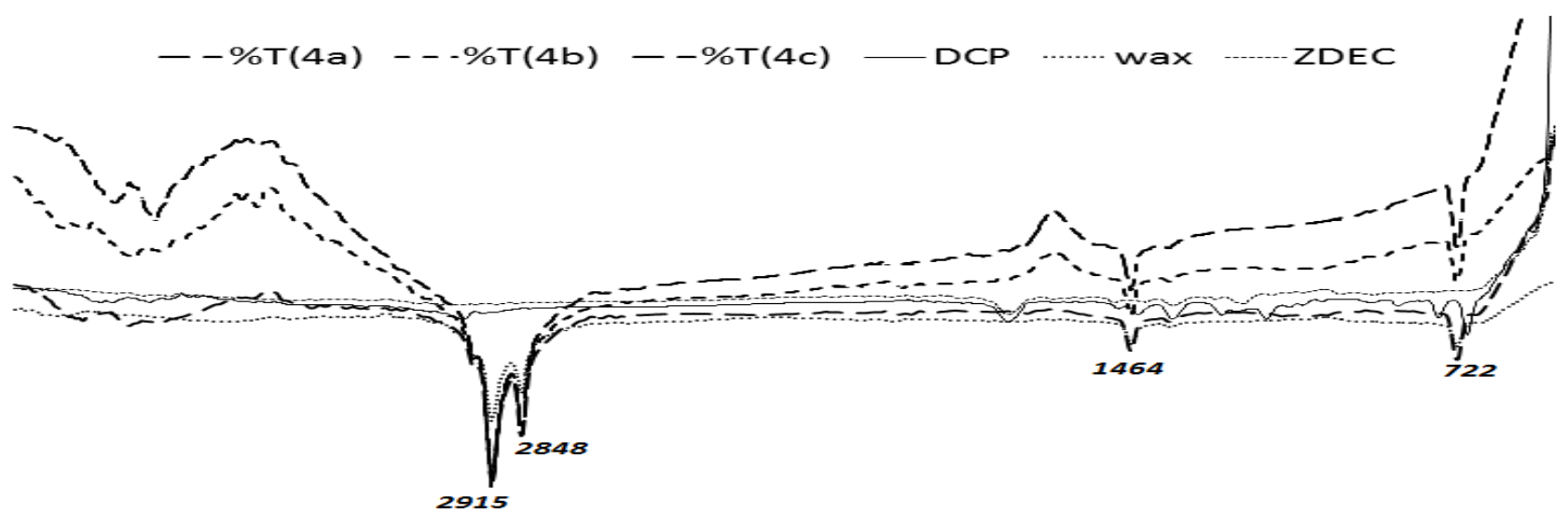

Fig.6. Overlay spectra of the bloom of V1, V2 and V3 vulcanizates; and control spectra of DCP, wax (paraffin wax) and ZDEC. 


\section{CONCLUSION}

As a conclusion, when sulfur, paraffin wax and ZDEC were added together in rubber compound in a mix vulcanization system as in this study; paraffin wax was found to be the dominant compounding ingredient that bloomed from the vulcanized rubber. Furthermore, blooming of paraffin wax was not hindered by the increased in concentration of peroxide cross-linker. Blooming is usually detrimental when sulfur is the bloom material. However blooming of paraffin wax induce desirable property. Paraffin wax acts as protective layer or anti-ozonant and can therefore be included in NRL products for anti-ageing property.

\section{ACKNOWLEDGMENT}

The authors would like to thank Research Management Centre (RMC) Universiti Teknologi MARA Shah Alam, grant number 600-IRMI/PERDANA 5/3/MITRA (003/2018)-1 for the financial support and Faculty of Applied Sciences, Universiti Teknologi MARA Shah Alam for the facilities provided.

\section{REFERENCES}

1. B. Pajarito, "Effect of Ingredient Loading on Surface Migration Kinetics of Additives in Vulcanized Natural Rubber Compounds,' Science Diliman, 2014, vol 2, pp 21-39.

2. A. Ansarifar, Critchlow, G. W., Guo, R., Ellis, R. J., Haile-Meskel, Y., \& Doyle, B. "Assessing Effect of the Migration of A Paraffin Wax on the Surface Free Energy of Natural Rubber," Rubber Chemistry and Technology, 2009, vol 82, pp 113-120.

3. F. Ignatz-Hoover, B. H. To, R. N. Datta, A. J. De hoog, N. M. Huntink, \& A. G. Talma, "Chemical Additives Migration in Rubber," Rubber Chemistry and Technology, 2003, vol 13, pp 747-768.

4. F. Saeed, R. J. Ellis, Y. Haile-Meskel, A. S. Farid, A. A. "Effect of the Blooming of Chemical Curatives on the Cyclic Fatigue Life of Natural Rubber Filled With Silica Nanofiller," Journal of Applied Polymer Science, 2011, vol 120, pp 2497-2507.

5. A. Bin Samsuri, "Degradation of Natural Ribber and Synthetic Elastomers," Shreir's Corrosion, Elsevier B.V, 2010, pp 2407-2438

6. U. Yasin, D. Kamarun, C. M. S. Said, A. Samsuri, "Effect of Compounding Ingredients and Crosslink Concentration on Blooming Rate of Natural Rubber Compounds," Advanced Materials Research, vol 1134, 2015, pp50-55

7. J. Arabit, "Effect of Ingredient Loading on Surface Migration of Additives in a Surfactant-Loaded Natural Rubber Vulcanizate,' Advanced Materials Research, vol 1125, 2015, pp 64-68.

8. F. Saeed, A. Ansarifar, L. I., J. Ellis, R. \& Y. Haile-meskel, “Assessing Effect of the Reagglomeration and Migration of Chemical Curatives on the Mechanical Properties of Natural Rubber Vulcanizate," Advances in Polymer Technology, vol 32, 2013, pp 153-165.

9. S. H. Nah and A. G. Thomas, "Migration and Blooming of Waxes to the Surface of Rubber Vulcanizates," Rubber Chem. Technol., vol. 54 no. 2, pp. 255-265, 1981.

10. A.P. Mathew, S. Packirisamy, M. G. Kumarant and S. Thomas, "Transport of styrene monomer through natural rubber", Polymer, Vol. 36 No. 26., 1995, pp. 4935-4942.

11. D.Vernon Neff, and H. Thomas Walnut, "Effect of Temperature on the Intensity and Structure of Bands in the Infrared Spectrum of Rhombic Sulfur.” The Journal of Chemical Physics, vol 35(5), 1961, pp 1723

\section{AUTHORS PROFILE}

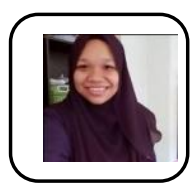

Ummu Qani'ah Binti Yasin completed her MSc. of Science by research in Polymer Technology at the Faculty of Applied Sciences, Universiti Teknologi MARA and her Bachelor of Science (Hons.) in Polymer Technology at the Faculty of Applied Sciences, Universiti Teknologi

MARA. Her publication is "Effect of Compounding Ingredients and Crosslink Concentration on Blooming Rate of Natural Rubber Compounds," Advanced Materials Research, vol 1134, 2015, pp 50-55. Her master project is focused in rubber research with title "The Blooming of Compounding Ingredients onto Natural Rubber Vulcanized Surface". Her previous working experiences in research are as Research Assistant at Iprus Sdn Bhd for 3 years on project of rubber masterbatch and as Research Officer at UiTM for 6month on project "Theoretical Investigation On TheMechanism of Tensile and Tear Strengths of Natural Rubber (NR) Latex Film”..

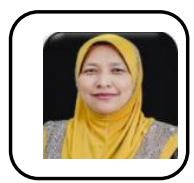

Engku Zaharah Engku Zawawi is a senior lecturer at the Universiti Teknologi MARA, Malaysia. She received her $\mathrm{PhD}$ and $\mathrm{MSc}$. from Universiti Kebangsaan Malaysia. She obtained her BEng in Polymer Engineering from University of North London, UK. Her research interests are polymer composites, thermoplastic elastomer nanocomposites, polymer blending and polymer processing.

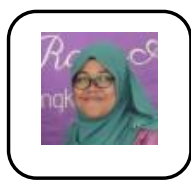

Noorazlina Adnan, MSc, is a lecturer at the Universiti Teknologi MARA, Malaysia. She has 9 years' experience in teaching chemistry and involved in writing several papers and laboratory manual. She was a research and development chemist in a glove company before she joined UiTM.

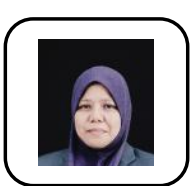

Hairani Tahir. Senior Lecturer at the Universit Teknologi MARA, Malaysia. She has published research articles in journals and proceedings. Her most recent published works was on Natural rubber Latex waste proteins for metal removal. She has over 19 years teaching and writing experience. Her PhD works is on Hevea protein applications.

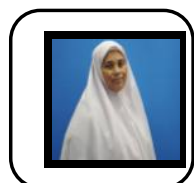

Dzaraini Kamarun, $\mathrm{PhD}$, is an Associate Professor cum Lecturer at the Universiti Teknologi MARA, Malaysia. She has experience in writing and editing academic literature for tertiary education and was the chief editor for her first published book, Progress in Polymer and Rubber Technology. She has published many research articles in journals and proceedings as well as in several local magazines. Her most recent published work was co-author the book entitled 'Tensile and Tear Strengths of Unfilled and Carbon-Black Filled NR' published by LAP Lambert Academic Publishing in 2018. She has over 30 years of teaching and writing experience. She received her $\mathrm{PhD}$ in Biosensors from the Queen Mary University of London, UK. 